\title{
Mechanical ventilation-induced 'pneumoangiogram' of cerebral vessels in a trauma patient
}

\author{
Lakshmikanth Halegubbi Karegowda, ${ }^{1}$ Satish Babu Maddukuri, ${ }^{2}$ \\ Poonam Mohan Shenoy, ${ }^{1}$ Swarna Kantipudi ${ }^{3}$
}

Department of Radiology, Kasturba Medical College, Manipal, Karnataka, India ${ }^{2}$ Department of Radiodiagnosis, Kasturba Medical College, Manipal Karnataka, India

${ }^{3}$ Department of Radiology and Imaging, Kasturba Medical College, Manipal, Karnataka, India

Correspondence to Dr Poonam Mohan Shenoy, drpoonamshenoy@gmail.com

Accepted 30 July 2014

\section{DESCRIPTION}

A 35-year-old male patient was referred to our trauma triage from an outside hospital with alleged history of head injury following a road traffic accident. While the patient was being transported to our hospital, he was in cardiorespiratory arrest and was intubated with vigorous ventilation by a manual bag. At the time of admission, he was unconscious and had a Glasgow Coma Scale of 3/15 with lacerations over the chin and the chest.

CT of the head revealed diffuse air embolism in the arteries of circle of Willis that was dramatically extending into the deeper parenchymal branches in bilateral cerebral and cerebellar hemispheres outlining the angiographic anatomy and giving a 'pneumoangiographic' appearance (figure 1). The patient also had diffuse axonal injury at the corticomedullary junction of the frontal lobes, corpus callosum and brainstem, with intraventricular haemorrhage in the left lateral ventricle (figures $1 \mathrm{C}$ and 2). Retrospective examination of the scanogram of head also revealed air lucency at the sites of cerebral vessels (figure 3). Within an hour of admission, the patient went into cardiac arrest and could not be revived.

Cerebral air embolism is usually seen as small millimetric hypodensities along the cerebral sulci on CT. ${ }^{1}$ A very few cases of large amounts of intravascular air outlining the angiographic anatomy of brain have been reported in the literature. ${ }^{2}$ Such rare phenomena are reported to occur due to two main reasons. First, they occur as a part of decompression sickness in divers; and second, they are iatrogenically induced as a complication of various medical procedures. ${ }^{2}$ Air embolism in our case was iatrogenically caused by pulmonary barotrauma due to vigorous mechanical ventilation leading to overdistention of the alveolar air sacs. This could have led to rupture of the air sacs with concomitant disruption of pulmonary vascular integrity. Tearing of the pulmonary veins during the process possibly has led to embolism of massive amount of air into the left chamber of the heart and then into the cerebral arteries. $^{3}$ We also suspect that trauma induced clinically occult lung injury would have aggravated the process as he had lacerations over the chest during clinical examination.
To cite: Karegowda $\mathrm{LH}$, Maddukuri SB, Shenoy P M, et al. BMJ Case Rep Published online: [please include Day Month Year doi:10.1136/bcr-2014205723

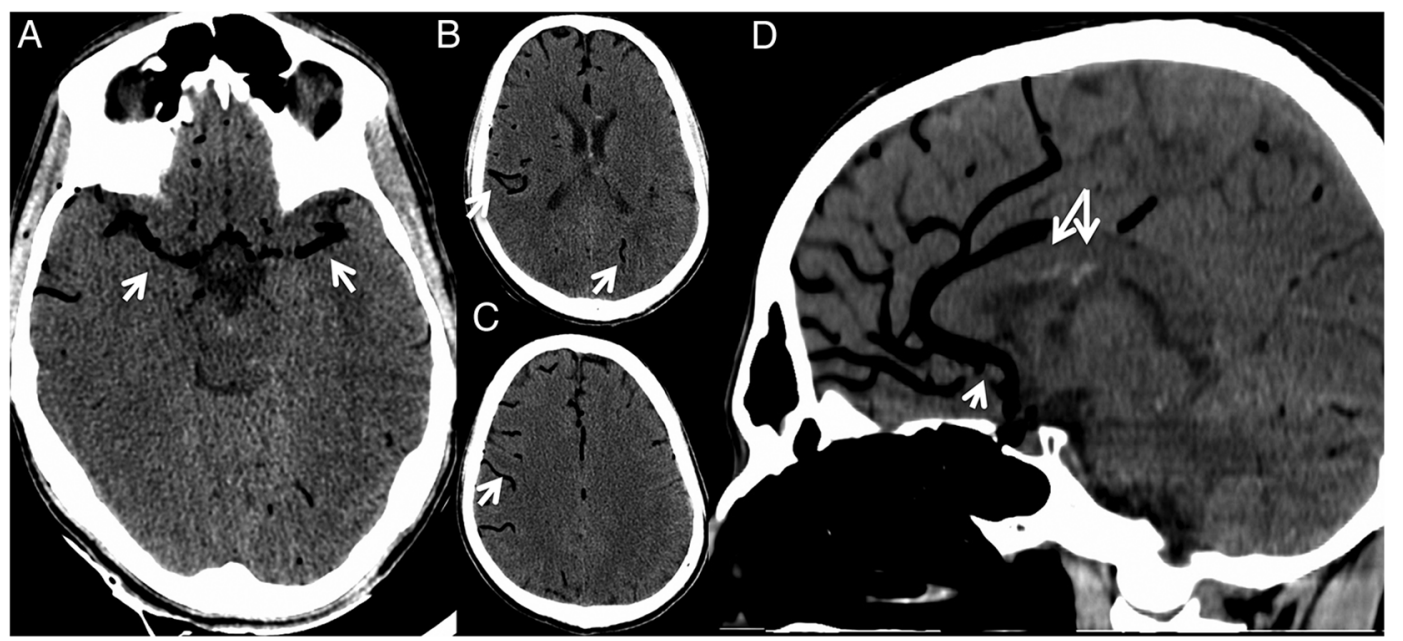

Figure 1 Axial CT of the brain showing hypodense intraluminal air outlining bilateral middle cerebral arteries (white arrows in A) and their cortical branches (white arrows in B and C). Sagittal CT image (D) showing the anterior cerebral artery and its branches outlined (white arrows). Also seen are hyperdensities along the inferior margin of corpus callosum (paired arrows in D) suggestive of diffuse axonal injury. 
Figure 2 Small hyperdense foci are seen at the grey-white matter junction of bilateral frontal lobes (arrows in A), inferior margin of corpus callosum (arrow in B) and along the dorsal aspect of the midbrain (arrow in C) suggestive of diffuse axonal injury. (D) Dependent hyperdensities in the occipital horn of the left lateral ventricle suggestive of intraventricular haemorrhage.

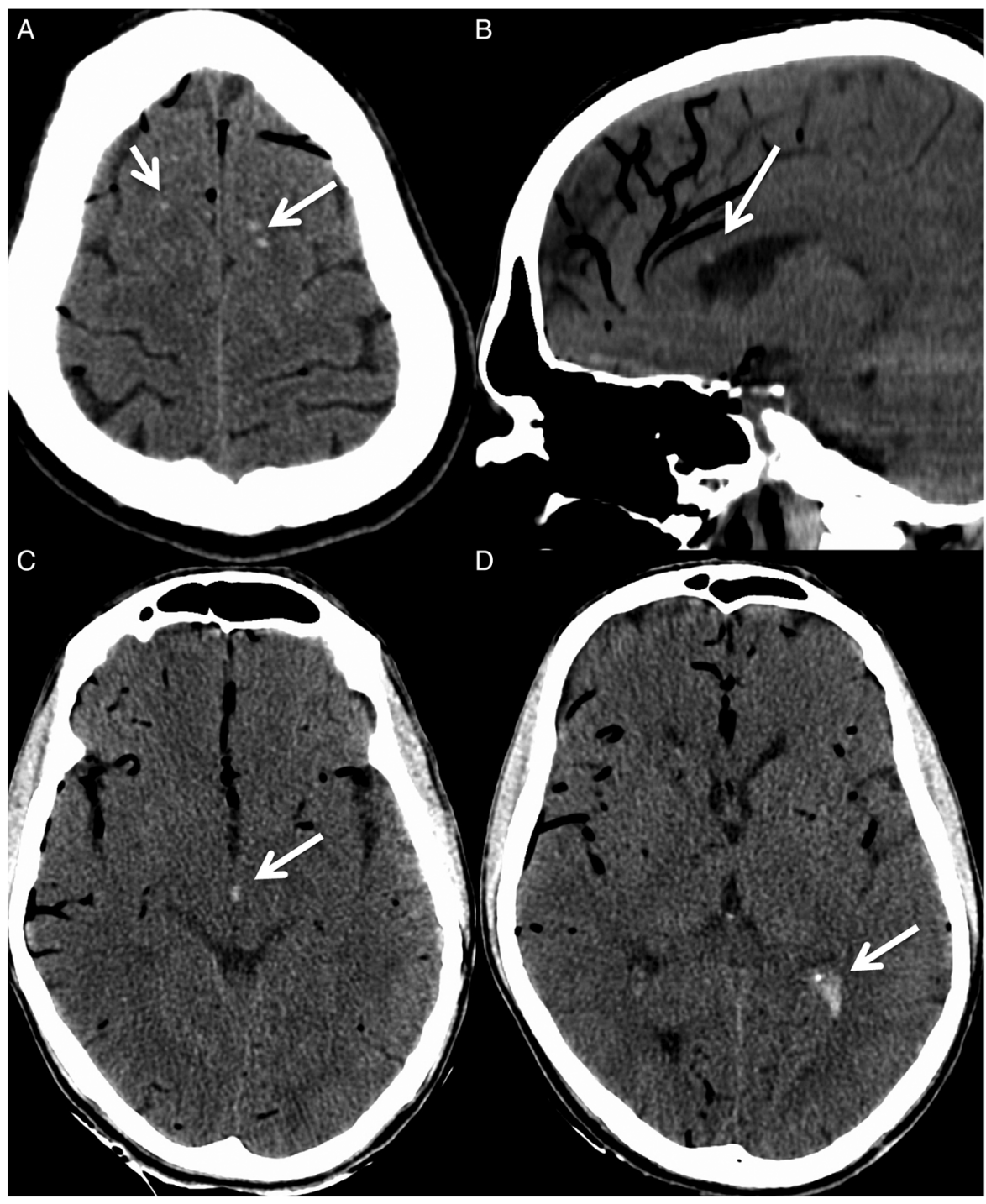

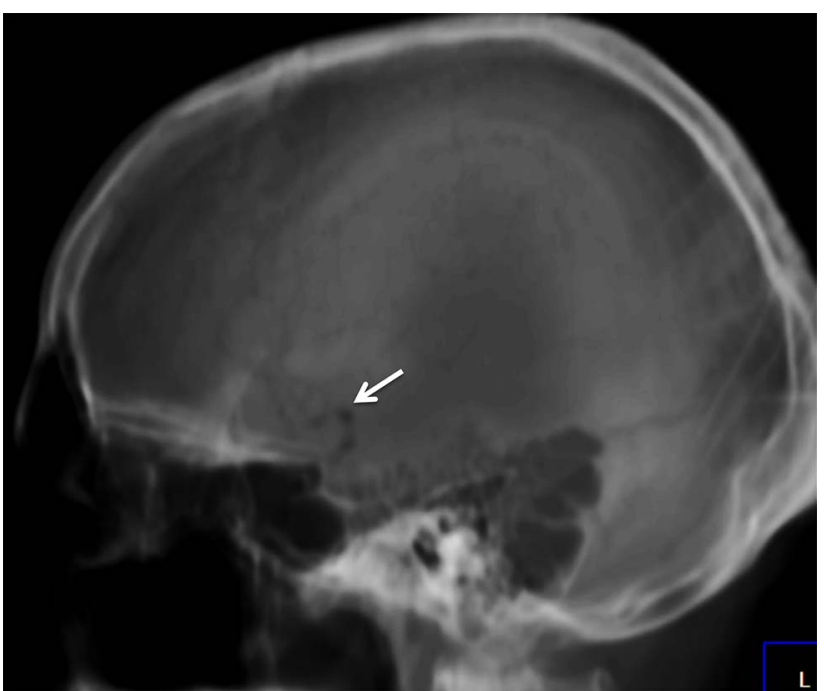

Figure 3 Air lucencies are also visible in the scanogram along the sites of cerebral vessels (white arrow).

\section{Learning points}

- Cerebral air embolism is a fatal condition of rare occurrence and mainly occurs either due to decompression sickness or from iatrogenic causes.

- latrogenic air embolism can be due to vigorous mechanical ventilation leading to rupture of the alveolar air sacs and pulmonary venules with air entering into the left heart chamber through the pulmonary veins.

- Cerebral air embolism is usually seen as small millimetric hypodensities along the cerebral sulci on CT and a very few cases of large amounts of intravascular air outlining the angiographic anatomy has been described.

Competing interests None.

Patient consent Obtained.

Provenance and peer review Not commissioned; externally peer reviewed. 


\section{REFERENCES}

1 Rivara CB, Chevrolet JC, Gasche Y, et al. Fatal brain gas embolism during non-invasive positive pressure ventilation. BMJ Case Rep. Published online: 20 Nov 2008. doi:10.1136/bcr.06.2008.0163.
2 Shiina G, Shimosegawa $Y$, Kameyam M, et al. Massive cerebral air embolism following cardiopulmonary resuscitation. Report of two cases. Acta Neurochir (Wien) 1993;125:181-3.

3 O'Dowd LC, Kelley MA. Air embolism. In: Post TW, ed. UpToDate. http://www. uptodate.com/contents/air-embolism

Copyright 2014 BMJ Publishing Group. All rights reserved. For permission to reuse any of this content visit http://group.bmj.com/group/rights-licensing/permissions.

BMJ Case Report Fellows may re-use this article for personal use and teaching without any further permission.

Become a Fellow of BMJ Case Reports today and you can:

- Submit as many cases as you like

- Enjoy fast sympathetic peer review and rapid publication of accepted articles

- Access all the published articles

- Re-use any of the published material for personal use and teaching without further permission

For information on Institutional Fellowships contact consortiasales@bmjgroup.com

Visit casereports.bmj.com for more articles like this and to become a Fellow 